\title{
VARIABILITY OF CORTICOSTEROID RESPONSES DURING EXERCISE STRESS IN ACTIVE AND SEDENTARY MIDDLE-AGED MALES
}

\author{
J. A. WHITE* A. H. ISMAILt, and G. D. BOTTOMSTt \\ *Department of Physical and Health Education, Baruch College, City University of New York, \\ 17 Lexington Avenue, New York, N.Y. 10010, U.S.A. \\ tDepartment of Physical Education (Men), Purdue University, West Lafayette, \\ Indiana, 47907, U.S.A. \\ t+Department of Physiology, School of Veterinary Medicine, Purdue University, \\ West Lafayette, Indiana, 47907, U.S.A.
}

Address correspondence to: Dr. John A. White, Department of Physical \& Health Education (Box 330) Baruch College (CUNY), 17 Lexington Avenue, New York, N.Y. 10010, U.S.A.

\begin{abstract}
Two groups of middle-aged male subjects (both $\mathrm{N}=11$ ), one active (mean age 44.6 years) and one sedentary (mean age 43.7 years), undertook a graded exercise stress test on a bicycle ergometer in the post-absorptive state. Blood serum 'corticosteroid levels were measured at the following stages of metabolism; at rest, under conditions of submaximal and "maximal" exercise and during recovery. The active group showed no significant change in mean serum corticosteroid levels from resting values, during exercise and recovery. However the sedentary group displayed a significant increase in mean serum corticosteroid levels from a resting value of $5.81 \pm 0.41 \mu \mathrm{g} / 100 \mathrm{ml}$. (mean $\pm \mathrm{S}$.E.) to $7.83 \pm 0.71 \mu \mathrm{g} / 100$ $\mathrm{ml}$. during "maximal" exercise $(\mathrm{p}<0.05)$, which was maintained throughout recovery $7.82 \pm 0.70 \mathrm{ug} / 100 \mathrm{ml}(\mathrm{p}<$ 0.05). Furthermore the active group demonstrated significantly lower mean serum corticosteroid levels compared with the sedentary group under conditions of submaximal $(p<0.05)$ and "maximal" $(p<0.01)$ exercise and during recovery $(p<0.01)$. It was concluded that the variability in the response patterns of serum corticosteroids during exercise stress in active and sedentary middle-aged males, reflected the physiological differences observed between the two groups of subjects.
\end{abstract}

\section{Introduction}

Studies concerning the effects of physical activity upon the structure and function of the adrenals in animals are well documented. Adrenal hypertrophy associated with chronic conditioning (2) and increased levels of circulating adrenal secretions resulting from acute exercise have been demonstrated $(2,3,22,23)$. Furthermore specific relationships have been observed between corticosteroid activity, facilitated carbohydrate metaboiism $(6,17,21)$ and muscular work performance $(10,12)$. It is now generally accepted that the corticosteroids play a vital role in the mechanism of adaptation of the organism to exercise stress.

However research in humans has not been characterised by agreement upon the precise pattern of the adrenocortical response to exercise stress. Several investigations have demonstrated a reduction in serum corticosteroids resulting from exercise $(4,5,14,18)$ whereas other work has failed to find any significant changes in the circulatory levels of these hormones (19). Alternatively, much evidence exists to support an increase in corticosteroid levels during or after exercise $(5,7,13,14,15,20,24)$. These differences in findings may be indicative of variability both in the experimental protocol utilised and the nature of subjects studied.
Moreover, relatively few studies have taken into account the influence of previous physical conditioning when attempting to explain experimental findings.

\section{Review of Literature}

Staehelin et al. (20) found that exercise consisting of a 2 hour bicycle ergometer ride at 100 Watts produced an increase in plasma corticosteroids at 15 and 30 minutes followed by a decline to $40 \%$ of starting values by the end of the work period. In contrast Cornil et al. (4) found that bicycle ergometer exercise of 20 minutes duration at 100 Watts in sedentary subjects resulted in a fall in plasma cortisol levels. Alternatively Raymond and co-workers $(18)$ demonstrated a $37 \%$ reduction in baseline values of serum corticosteroids in subjects who exercised on a treadmill for $\mathbf{3 0}$ minutes at $3 \mathrm{mph}$ on a $5 \%$ positive grade.

A study by Rose et al. (19) showed no significant difference between control levels of plasma cortisol and those obtained upon completion of a mile run in conditioned subjects. However Wenzkat et al. (24) using trained sportsmen found elevated plasma cortisol levels when subjects were exercised to exhaustion. Lehnert, 
Lieber and Schaller (13) reported an immediate rise in plasma corticosteroids during graduated exercise of 100 to 150 Watts for 9 to 15 minutes of bicycle ergometer work.

A number of studies provide evidence that corticosteroid secretions in exercise may be dependent upon the degree of work load in relation to the subject's maximal work output rather than the absolute amount of work performed. Métivier et al. (15) found similar increases in plasma cortisol levels in trained individuals who exercised at $50 \%$ and $60 \%$ of their $\mathrm{VO}_{2}$ max. Harley and co-workers (7) determined the effect of graded exercise involving work loads of $42 \%, 75 \%$ and $98 \%$ of $\mathrm{VO}_{2}$ max on plasma cortisol levels and observed no increase above resting values except during the heaviest work load. Davies and Few (5) found that during 60 minutes of treadmill exercise, a work load of approximately $60 \% \mathrm{VO}_{2}$ max appeared to be the critical level above which a rise in plasma cortisol occurred.

The effect of physical conditioning on plasma cortisol levels during $\mathbf{3 0}$ minutes of bicycle ergometer work at $750 \mathrm{kpm}$ and $60 \mathrm{rpm}$ was investigated by Métivier et al. (14). Untrained individuals demonstrated progressive increases in plasma cortisol whereas trained individuals showed an initial increase followed by no change during the work period. Alternatively, Hartly and co-workers (8) assessed the effect of a 7 week training programme on the plasma cortisol response to exhaustive bicycle ergometer exercise of moderate intensity but found no significant differences between pre- and post-test training response patterns.

In the present study we have determined the serum corticosteroid level in active and sedentary groups of middle-aged male subjects during consecutive periods of rest, submaximal and "maximal" exercise, and during recovery, in order to measure the variability of response patterns associated with physical conditioning.

\section{Methods}

Subjects. Twenty two male subjects, ages 27-57 years, were used in the study. All were faculty members of Purdue University and participants in an adult physical fitness programme. Each subject gave his written consent and had undergone a complete medical examination before participating in the study. Two groups were established, one active and one sedentary (both $\mathrm{N}=11$ ) using physical fitness scores obtained on each individual according to the fitness criterion of Ismail et al. (11). The criterion consists of a regression equation containing six variables which have a high predictive value when assessing physical fitness $\left(R^{2}=.881 ; R=.939\right)$. These are as follows:
Item Beta Weigft

1. Exercise heart rate

2. Percent lean body weight

3. Maximum oxygen uptake $\mathrm{ml} / \mathrm{kg}$ lean body mass

4. Submaximal minute volume ventilation $/ \mathrm{kg}$ body weight

5. Resting diastolic blood pressure

6. Resting pulse pressure

Constant

The physical characteristics of the two groups subjects are presented in TABLE I.

Table I. Physical characteristics of the two groups of subjects who participated in the study.

$$
\begin{array}{ll}
\text { Active Group } & \text { P } \\
\text { Mean } \pm \text { S.E. } & \text { (A }
\end{array}
$$

Age yr.

Height cm.

Weight $\mathbf{k g}$.

$\%$ lean

$\begin{array}{rr}44.6 \pm 2.5 & \text { N.S. } \\ 181.3 \pm 1.6 & \text { N.S. } \\ 82.9 \pm 3.4 & 0.01 \\ 84.2 \pm 1.6 & 0.01\end{array}$

Sedentary Group

Mean \pm S.E.

$43.7 \pm 2.5$

$182.9 \pm 2.2$

$102.3 \pm 7.8$

$77.1 \pm 1.2$

The Physical Fitness Test. On reporting to the laboratory each subject was allowed to rest for 10 minutes in the supine position after which cardiac frequency, blood pressure, height, weight and percens lean body weight were recorded. The subject then performed a submaximal ride of 10 minutes duration of a bicycle ergometer (Monark, Sweden) at a work load of $600 \mathrm{kpm}$ and pedalling frequency of $50 \mathrm{rpm}$. This was followed immediately by a bout of "maximal" exercise which involved an increase in the work load of $150 \mathrm{kpm}$ $\min ^{-1}$. In order to establish a "maximal" response, safety criterion cardiac frequency value of 160 beatङ $\min ^{-1}$. was employed (1), or prior to this, if the subject indicated that he was exhausted and could no longe maintain the required pedalling frequency. After tha exercise had been completed, the subject spent 15 minutes in recovery in the supine position.

Venous blood samples were drawn from thळ antecubital vein at rest, during submaximal and maximab exercise and following recovery. Serum was separated frozen and later analysed for corticosteroid? concentration. The subject's respiratory and cardiaco responses were monitored at each stage of exercise and $\mathrm{VO}_{2}$ and $\mathrm{fH}$ were determined. The physiologica品 responses of the two groups of subjects during the physical fitness test are presented in TABLE II.

All subjects were studied in the post-absorptive state between 0800 and 1200 hours in order to minimise the 
Table II. Physiological responses of the active and sedentary groups of subjects

\begin{tabular}{lll} 
Cardiac frequency & Resting \\
(Beats $\left.\mathrm{min}^{-1}\right)$ & Oxygen intake & Blood Pressure \\
\hline
\end{tabular}

\begin{tabular}{|c|c|c|c|c|c|c|c|c|}
\hline & Rest & Submax & Max & Submax & Max & Syst. & Diast. & Pulse \\
\hline $\begin{array}{l}\text { Active Mean } \\
\pm \text { S.E. }\end{array}$ & $\begin{array}{l}58.7 \\
\pm 2.4\end{array}$ & $\begin{array}{r}110.0 \\
\pm 4.1\end{array}$ & $\begin{array}{r}157.3 \\
\pm 3.8\end{array}$ & $\begin{array}{l}22.6 \\
\pm 1.2\end{array}$ & $\begin{array}{l}45.4 \\
\pm 1.6\end{array}$ & $\begin{array}{r}126.4 \\
\pm 4.3\end{array}$ & $\begin{array}{r}77.8 \\
\pm 1.7\end{array}$ & $\begin{array}{l}47.7 \\
\pm 2.9\end{array}$ \\
\hline$P($ Act - Sed $)$ & 0.05 & 0.01 & N.S. & N.S. & 0.01 & N.S. & 0.01 & N.S. \\
\hline $\begin{array}{l}\text { Sedentary Mean } \\
\pm \text { S.E. }\end{array}$ & $\begin{array}{l}66.7 \\
\pm 2.8\end{array}$ & $\begin{array}{r}124.4 \\
\pm 5.4\end{array}$ & $\begin{array}{l}154.6 \\
\pm 2.4\end{array}$ & $\begin{array}{l}24.8 \\
\pm 2.0\end{array}$ & $\begin{array}{l}36.4 \\
\pm 2.0\end{array}$ & $\begin{array}{r}133.1 \\
\pm 3.6\end{array}$ & $\begin{array}{l}88.7 \\
\pm 3.5\end{array}$ & $\begin{array}{l}44.4 \\
\pm 2.2\end{array}$ \\
\hline
\end{tabular}

effects of diurnal variation (9). Furthermore each subject was familiarised with the bicycle ergometer test before the investigation.

Oxygen intake $\left(\mathrm{VO}_{2}\right)$. The subjects inspired through a 3-way " $\mathrm{J}$ " valve and expired air was collected during the last 30 seconds of each exercise bout in a 150 litre Tissot gasometer equipped with a kymograph. All volumes of expired air were corrected to STDP and duplicate samples were analysed for $\mathrm{O}_{2}$ and $\mathrm{CO}_{2}$ using a Beckman 777 oxygen analyser and a Beckman B1-1 medical gas analyser respectively. Both instruments were calibrated at frequent intervals using commercial gas mixtures of known concentrations which had been checked using the micro-Scholander apparatus.

Cardiac frequency (fH). Cardiac frequency was monitored at rest and throughout the exercise period using a stethoscope placed at the apex of the heart. The rate per minute was noted during the last minutes of each stage of exercise.

Percent lean body weight (\% lean). The percentage of lean body weight was estimated using the method of Wilmore and Behnke (25).

Blood pressure. Blood pressure was recorded using a standard clinical sphygmomanometer and a stethoscope placed over the brachial artery. Systolic and diastolic pressures were noted and pulse pressure determined.

Serum Corticosteroids. Blood samples were centrifuged at 3,000 rpm for 10 minutes and serum was separated and kept frozen until analysed. Total serum corticosteroid concentration (cortisol and cortisone) was measured by a modification of the competitive protein-binding technique of Murphy (16).

The time course of changes in mean cardiac frequency and oxygen intake for the active and Results

sedentary groups during different stages of exercise is shown in Figure 1 . 


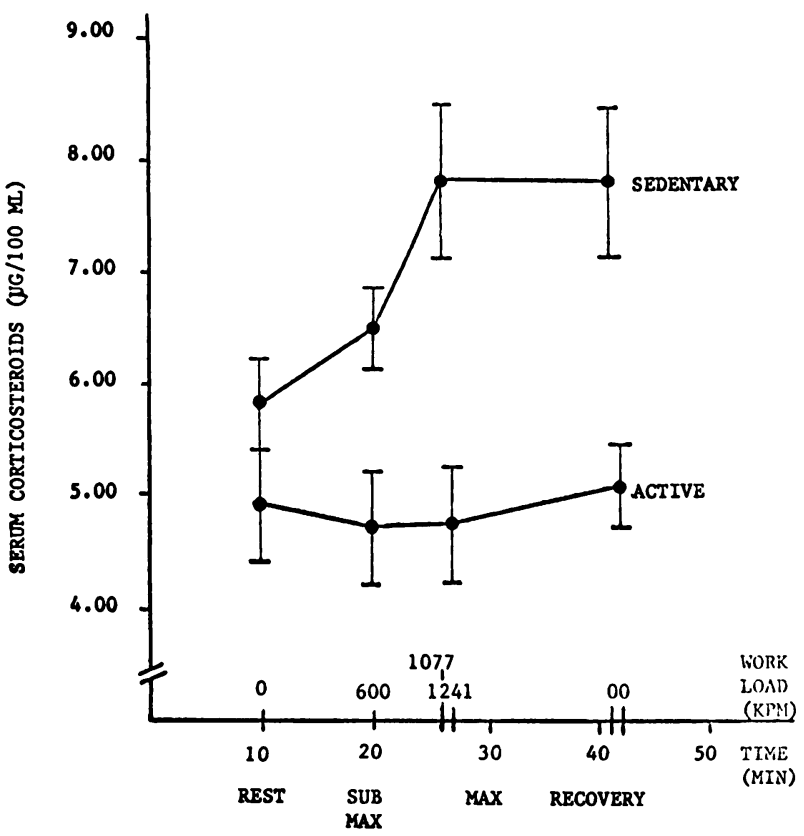

Figure 2. Mean ( \pm S.E.) serum corticosteroid concentrations of the active and sedentary groups at different stages of exercise.

mean corticosteroids neither during exercise nor during recovery. In contrast the sedentary group displayed a significant rise in mean corticosteroids from a resting value of $5.81 \pm 0.41 \mu \mathrm{g} / 100 \mathrm{ml}$, during maximal exercise, $7.83 \pm 0.71 \mu \mathrm{g} / 100 \mathrm{ml}(\mathrm{p}<0.05)$ which was maintained during recovery, $7.82 \pm 0.70 \mu \mathrm{g} / 100 \mathrm{ml}(\mathrm{p}<$ 0.05). Furthermore the active group had significantly lower mean corticosteroids than the sedentary group during submaximal exercise $(p<0.05)$, maximal exercise $(p<0.01)$ and recovery $(p<0.01)$ as shown in TABLE III.

Table III. Comparison of serum corticosteroids $(\mu \mathrm{g} / 100$ $\mathrm{ml}$ ) of the active and sedentary subjects during different stages of exercise

$\begin{array}{llll} & \begin{array}{l}\text { Active Group } \\ \text { Mean } \pm \text { S.E. }\end{array} & \begin{array}{l}\text { P } \\ \text { (Act }- \text { Sed) }\end{array} & \begin{array}{l}\text { Sedentary Group } \\ \text { Mean } \pm \text { S.E. }\end{array} \\ \text { Rest } & 4.91 \pm 0.51 & \text { N.S. } & 5.81 \pm 0.41 \\ \text { Submax } & 4.73 \pm 0.51 & 0.05 & 6.50 \pm 0.41 \\ \text { Max } & 4.76 \pm 0.52 & 0.01 & 7.83 \pm 0.71 \\ \text { Recovery } & 5.11 \pm 0.39 & 0.01 & 7.82 \pm 0.70\end{array}$

\section{Discussion}

The results of this study demonstrate that the response pattern of serum corticosteroids to exercise is partly dependent upon the fitness status of the subjects tested.

In the case of the sedentary group the early rise in corticosteroids showed that graded exercise to near exhaustion resulted in physiological stress in these subjects which persisted throughout the recovery period. $\frac{\text { के }}{2}$ However since no such response was observed in the case of the active group, leads us to suggest that the active group were more able to tolerate the physiological stress $\overrightarrow{\vec{F}}$ imposed by the exercise. No doubt this was due in part to the fact that the exercise was not so exhaustive for the active group since the same criterion of a "maximal" response was employed for both groups of subjects,, namely a cardiac frequency of 160 beats min $^{-1}$.

Most investigations cited in this study have beenis restricted to groups of subjects who were classified $\vec{\circ}$ either as sedentary $(4)$ or active $(15,19,24)$, or moregenerally as "normal healthy" subjects $(13,18,20) . \vec{\omega}$ However a study by Métivier (14) noted lower? corticosteroid levels in trained subjects compared witho untrained subjects who performed steady state exercise, a finding which tends to be supported by our results. Furthermore it is suggested that the exercise stressi tolerance exhibited by the active group in comparison? with the sedentary group appeared to be related to theirenhanced fitness status. Indeed the difference in the response patterns of corticosteroids during exercise stress between the active and sedentary groups are $\vec{\circ}$ reflective of the physiological differences between the of two groups of subjects (TABLE II). Therefore the phenomenon of exercise stress tolerance may be relatedo to the chronic effects of physical conditioning since it was ascertained by personal interview, following fitness classification, that the groups of subjects selected had been "active" and "sedentary" since early adulthood.

The rise is corticosteroids during exercise in the 3 sedentary group may possibly be explained in terms of findings from other investigations which suggest $a$. relationship between increased corticosteroid secretion and the relative intensity of work performed during? exercise viz. the percentage of maximal aerobic powero required to perform the work load $(5,7,8)$. Such studies have found that work performed toward the upper limits of maximal aerobic power is associated with increased $\$$ corticosteroid secretion. Therefore the significanto increases in corticosteroid levels observed in the sedentary subjects in this study, which were associatedo with relatively heavy work loads considered as near "maximal" for these subjects, would appear to supporto the above findings. However, in the case of the activen subjects, the intensity and duration of work required ton elicit the criterion cardiac frequency probably $y_{0}^{\omega}$ represented a "high steady state" of work which was not sufficiently demanding upon aerobic power to result inc an adrenocortical response in this group.

The experiments described in this paper were approved by the Committee on the Use of Human Subjects in Research at Purdue University.

The study was supported by Grant No 6562/56-13615 sponsored by the Purdue Research Foundation. 


\section{REFERENCES}

1. BALKE, B., The effect of physical exercise on the metabolic potential, in: Exercise and Fitness, Chicago, Illinois, The Athletic Institute, 1960, p. 74.

2. BUUCK, R. J. and G. D. THARP. Effect of chronic exercise on adrenocortical function and structure in the rat. J.Appl.Physiol., 31: 880-883, 1971.

3. CHIN, A. K. and E. EVONUK. Changes in plasma catecholamines and corticosterone levels after muscular exercise. J.Appl.Physiol., 30: 205-207, 1971.

4. CORNIL, A., A. DECOSTER, G. COPINSCHI and J. R. M. FRANCKSON. The effect of muscular exercise on the plasma cortisol level in man. Acta Endocrinol, 48: 163-168, 1965.

5. DAVIES, C. T. M. and J. D. FEW. Effects of exercise on adrenocortical function. J.Appl.Physiol., 35: 887-891, 1973.

6. DAW, J. C., A. M. LEFER and R. M. BERNE. Influence of corticosteroids on cardiac glycogen concentration in rats. The Physiologist, 10: 153, 1967.

7. HARTLEY, H. L., J. W. MASON, R. P. HOGAN, L. G. JONES, T. A. KOTCHEN, E. H. MOUGEY, F. E. WHERRY, L. L. PENNINGTON and P. T. RICKETTS. Multiple hormonal responses to graded exercise in relation to physical training. J.Appl.Physiol., 33: 602-606, 1972.

8. HARTLEY, H. L., J. W. MASON, R. P. HOGAN, L. G. JONES, T. A. KOTCHEN, E. H. MOUGEY, F. E. WHERRY, L. L. PENNINGTON and P. T. RICKETTS. Multiple hormonal responses to prolonged exercise in relation to physical training. J.Appl.Physiol., 33: 607-610, 1972.

9. HELLMAN, H. L., F. NAKADA, J. CURTI, E. D. WEITZMAN, J. KREAM, H. ROFFWARD, S. ELLMAN, D. K. FUKUSHIMA and T. F. GALLAGHER. Cortisol is secreted episodically by normal man. J.Clin.Endocrinol., 30: 411-422, 1970.

10. INGLE, D. J., J. E. NEZAMIS and E. H. MORLEY. The work performance of normal rats given continuous intravenous injections of cortisone and corticotropin. Endocrinol., 51: 487-491, 1952.

11. ISMAIL, A. H., H. B. FALLS and D. F. MACLOED. Development of a criteroin for physical fitness tests. J.Appl.Physiol., 20: 991-999, 1965.

12. LEFER, A. M. Influence of corticosteroids on mechanical performance of isolated rat papillary muscles. Amer.J.of Physiol., 214: 518-524, 1968.

13. LENHERT, G., H. LEIBER and K. H. SCHALLER. Plasma-cortisol und plasma corticosteron im Anpassungsstadium der dosierten Korperlichen Arbeit. Endokrinologie, 52: 402-405, 1968.

14. MÉTIVIER, G., G. BRISSON, J.-P. DES GROSSEILLIERS. Blood biomechanical changes in man associated with physical training, in: Exercise and Fitness, Chicago, Illinois, The Athletic Institute, 1969, pp. 67-81.

15. MÉTIVIER, G., J. POORTMANS, R. VANROUX, P. LECLERO and G. COPINSCHI. Arterial blood plasma cortisol and human growth hormone changes in male trained subjects submitted to various physical work intensities. Med. and Sci. in Sports, Abs. 3 (1): g. Spring, 1971.

16. MURPHY, B. E. P., Protein binding and the assay of non-antigenic hormones. Rec.Prog.Horm.Res., 25: 565-610, 1969.

17. PALMER, B. G. The effect of cortisol on body weight and muscle metabolism in the rat. J.Endocrinol., 36: 73-83, 1966.

18. RAYMOND, L., J. SODE and J. TUCCI. Adronocortical response to exercise. Clin. Res., 17: 523, 1969. 
19. ROSE L I H S. FRIEDMAN S C. BEERING and K H COOPER. Plasma cortisol changes following a mile ru in conditioned subjects. J.Clin. Endocrinol.; 31: 339-341, 1970.

20. STAEHELIN, D., A. LABHART, R. FROESCH, and E. R. KÄGI. The effect of muscular exercise and $\stackrel{\overline{\vec{s}}}{\overrightarrow{5}}$ hypoglycemia on the plasma levels of 17-hydroxycorticosteroids in normal adults and in patients with the adrenogenital syndrome. Acta Endocrinol., 18: 521-529, 1955.

21. STRUCK, P. J. and C. M. TIPTON. Glycogen changes in exercised and non-exercised adrenalectomized rats. Med. and Sci. in Sports, Abs. 3 (1): e. Spring 1971.

22. SUZUKI, T., K. OTSUKA, H. MATSUI, S. OHUKUZI, K. SAKAI and Y. HORADA. Effect of muscular exercise on $\vec{\circ}$ adrenal 17-hydroxycorticosteroid secretion in the dog. Endocrinol., 180: 1148-1151, 1967.

23. VIRU, A. and H. AKKE. Effects of muscular work on cortisol and corticosterone content of the blood and adrenals of guinea pigs. Acta Endokrinol., 62: 385-390, 1969.

24. WENZKAT, P. B., W. HUBL, K. R. KIRSCH and M. BÜCHNER. Die Wirkung von Muskelarbeit auf den Harnund Plasmaspiegel der unkonjugierten 11-Hydroxykortikosteroide. Acta Biol.Med.Ger., 21: 163-168, 1968.

25. WILMORE, J. H. and A. R. BEHNKE. An anthropometric estimation of body density and lean body weight in young men. J.Appl.Physiol., 27: 25-31, 1969.

\section{OBITUARY}

\section{Dr. Michael J. Keating, MB, ChB, BAO, MRCGP, JP}

We are distressed to learn of the sudden death of Mike Keating on December 27th 1974, in Hartlepool. He qualified at the National University of Ireland in 1940, from Cork Medical School, then went to Sunderland Royal Infirmary as House Officer in Surgery then in Orthopaedics. When I worked at that hospital in 1944, Mike Keating was already a legendary figure, and I met him soon afterwards, from whence we were lifelong friends. He served in the Burma campaign towards the end of the war, and was one of the few medical officers to penetrate deeply into enemy-held jungle for prolonged action. His fitness as a rugby football player, and boxer stood him in good stead for this type of work, and he maintained a keen interest as an active sportsman for many years, then as a doctor serving in both medical and administrative capacities in sports clubs, for the whole time he was in general practice from the end of the war until his death at the end of a surgery.

He joined B.A.S.M. in 1962, and soon afterwards organised meetings for our Association in the North East of England, being responsible for setting up the North East Area of B.A.S.M. During the past few years, however, bad health had forced him to give up much of the voluntary work he so enjoyed, and there could be no more fitting memorial that B.A.S.M could make than to see the Area Organisation resuscitated and again active under new leadership.

H. E. Robson 